\title{
Online Drug Scenes and Harm Reduction From Below as Phronesis
}

\author{
Dave Boothroyd' and Sarah Lewis'
}

\begin{abstract}
This article presents a theoretical critique of the notion of harm reduction on the basis of an empirical investigation of a variety of online manifestations of drug culture. Taking a multicase study approach to drug use-related forums, blogs, and "story sites" focused on novel psychoactive substances/"legal high" use and nonmedicinal prescription drug use, our analysis leads us to describe the culture of "harm reduction from below" in terms of the Aristotelian concept of phronesis. We argue that the peer-topeer co-creation of knowledge, sharing, and support constitutes an emergent and constantly evolving form of "practical wisdom" with respect to drugs. Drawing on Flyvbjerg's accounts of phronetic social science as a practice, which proposes a permeable boundary between theoretical and practical inquiry, and Stenger's account of the "collective voice from below" as always embedded within an "ecology of practices," we offer an interpretation of the online dimension of drug taking in terms of drug users' shared aim of "doing drugs well." The investigation of online life in terms of the multiple contexts of drug-related communicative exchange thus allows us to identify harm reduction from below as an ethical practice inherent in a variety of online drug scenes.
\end{abstract}

\section{Keywords}

harm reduction, online life, phronesis, ethics, Flyvbjerg

Only life can teach you how to live, and then, only if you get to live long enough.

Tony Bennett on the death of Amy Winehouse ${ }^{1}$

\section{Introduction}

While only malevolence could logically be opposed to "harm reduction," it is everywhere apparent that in social drug research and in policy, the efficacy of the concept and the practice of harm reduction are highly contested. The reasons for this are many and are perhaps nowhere better laid out than by Helen Keane (2003) in an article that explains the imbrications of harm reduction with

\footnotetext{
'School of Film and Media, University of Lincoln, Lincoln, UK

Received January 12, 2016. Accepted for publication May 19, 2016.

\section{Corresponding Author:}

Dave Boothroyd, School of Film and Media, University of Lincoln, Brayford Pool, MHT, Lincoln, Lincolnshire LN6 7TS, UK. Email: dboothroyd@lincoln.ac.uk
} 
the complex ethical and political dimensions of its theorization and its policy implications and practice. Keane eloquently illustrates how all parties to the debate on illicit drug use and "what to do about it" - from drug use libertarians through to anti-drug campaigners - are apt to deploy the conceptual resources of modern critical thought to claim the mantle of harm reduction. They do this, for instance, whenever the harms associated with both illicit drug use and drug policy are understood in terms of the suffering caused and endured or whenever a cost-benefit analysis of harm reduction strategies becomes the basis for calculating likely outcomes-very much along the lines of the consequentialist utilitarianism of Jeremy Bentham and John Stuart Mill. They also do this when they invoke the rationalist principle of individual freedom as both a foundational value to be defended and the ground upon which all forms of "control," including drug use controls, must be assessed and evaluated. But when the discussion of harm reduction proceeds along these lines, Keane (2003) is clear, all roads eventually lead back to the question of who (or what) has the authority to define harm reduction.

Human rights discourse is no more helpful in resolving the question of who has such authority to define harm reduction, for it is fraught with irresolvable contradictions. For instance, if the actual reduction of harm is adjudged to be a purely empirical matter, then this is likely to conflict with the notion of the a priori right to liberty - namely, for the individual to do as he or she chooses. Individual human autonomy effectively remains the unexamined ground of the human rights perspective, but it is in fact an unrealizable ideal and thinking gets stuck, as Deleuze and Guattari (1987) might say, on the plane of critique, which could also be considered a kind of place or "territory" (MacKenzie, 2004, p. 48) - the significance of which will become clear as we proceed. There will therefore always be a "tension between a demand for care and protection by the state and a demand for freedom from state regulation" (Keane, 2003, p. 230). What the state grants with one hand is what it is already taking away with the other, not least because any claim to, or assertion of, authority-underpinning control over drugs and drug-taking - always begs the question of its legitimacy. As Judith Butler (1997) states in her discussion of censorship, any claim to, or supposition of, the sovereignty of a power (e.g., a state) is in reality a pretension disguising the fact that it can no more guarantee the freedom of the subject which it produces than it can its freedom from anything it is exposed to or has access to.

In this way, high-minded moralistic approaches to harm reduction - of either libertarian or antidrug persuasions - can be argued to come from on-high (and always expressed via the "grander narratives" of freedom and morality, according to Keane). They both belong to an epistemic-juridical plateau above everyday life "drug worlds," within which patterns of compulsion, recreation, and experimentation play out vis-à-vis drugs and drug use in a multitude of singular, actual situations. Some of these drug scenes may well include both reflection on and practical strategies for "less harmful drug-taking" on the part of the drug takers who populate them, with regard to their own immediate concerns for the implementation of "harm reduction" in situ. (And "harm reduction" is just one dimension of what it means to "do drugs well" or "badly," from the perspective of users who may be in pursuit of a variety of effects.) In any case, users make choices in such contexts without waiting for supposedly sovereign powers to act on their behalf. Users act pragmatically from within the diversely contextualized settings of drug-taking itself. Furthermore, if the reduction of harm is simply asserted to be a de facto ethical good, then this is, arguably, just another kind of "pretension" insofar as it hides the fact that we are only ever able to think this equation of ethicality with the reduction of harm on the basis of the problematic entwinement of harm reduction as an idea with the concrete reality of drug-taking as a practice.

Keane (2003) is therefore correct to cite Stengers and Ralets' (1997) attention to the milieu of drugtaking as central to a radical break with the familiar moralism and repetitive moralizing around the thematic of harm reduction. The importance of the concept of the milieu is twofold. First, there is simply no such thing as a "drug-free cultural milieu" (for the cultural whole is always already given, as much as by anything else, by its delimitation of drugs and its relations to them). ${ }^{2}$ Second, there is 
simply no place (lieu) from which to morally pontificate on the matter. If there is no clear divide between "drug culture" and the rest of culture, it would be inconsistent not to acknowledge that the cultural resources for critically conceptualizing and debating harm reduction were themselves not already shaped by the broader cultural totality of which drugs are a determining part (see Boothroyd, 2006). So, rather than interminably revisiting and repeating the arguments surrounding its definition in the discourse of consequences versus rights, or anticipating a philosophical and theoretical resolution of the conundrum, the discussion must move toward the rethinking of the "ethics of harm reduction" at the pragmatic level of actual drug scene milieus (of which, we aim to show, online drug culture is an important dimension). In such scenes, which give form and content to a milieu, the morality of drugtaking, at least in the above senses, is simply not an issue. But it remains an ethical matter in a deeper sense and requires to be understood in an entirely different register-for example, in terms of the ethical subjectivities that specific drug scene milieus give rise to. Thinking harm reduction, and understanding the subjectivities wrapped up in it, must therefore proceed in conjunction with the milieu (Stengers, 2005). ${ }^{3}$

Elsewhere, Stengers (2008) explicitly expresses her own indebtedness to the "collective voice from below" of drug user groups and references this in relation to her account of the pragmatics of subjectivity and its production in general:

My own intellectual and political life has been marked by what I learned from the appearance of drugs users' groups claiming that they were "citizens like everyone else," and fighting against laws that were officially meant to "protect" them. The efficacy of this new collective voice, relegating to the past what had been the authorized, consensual expertise legitimating the "war on drugs," convinced me that such events were "political events" par excellence, producing ... both new political struggle and new important knowledge. I even proposed that what we call democracy could be evaluated by its relation to those disrupting collective productions (Stengers \& Ralet, 1997). A "true" democracy would demand the acceptance of the ongoing challenge of such disruptions - would not only accept them but also acknowledge those events as something it depended upon. (Stengers, 2008, p. 39)

We cite Stengers' (2008) account of the conjunction of the "collective voice," "democracy," and the disruption of "consensual expertise" to set the scene for the discussion of our empirical research into a variety of online drug scenes - or "settings" as we refer to them. We argue below that not only do peer-to-peer Internet communications around drugs and drug use produce alternative knowledges and forms of expertise, but that it is possible to discern across various digital milieus the emergence of forms of "practical wisdom" about drugs and drug use. This practical wisdom is a dimension of lives lived "on drugs" in conjunction with various modes of mediation.

By "practical wisdom," we allude to the Aristotelian sense of phronesis, a form of knowing that combines the performance of one's "well-being" with an ethical sense of pursuit of the "good life" (as distinct from episteme, which corresponds to scientific knowledge, and techne, which corresponds to skill or craft). ${ }^{4}$ Our purpose in deploying this terminology stems from the desire to think through the ethics of harm reduction from the perspective of drug-taking itself, as it were, and to do so on the basis of an evidence base both constituted and rendered analyzable by virtue of its manifestation, expression, and publicity as online drug culture. Through an analysis of the data collected over an 11-month period from a cross section of drug use web forums, blogs, and story sites, our study aims to better understand how "harm reduction from below" is being practiced - an analysis which eschews the ultimately alltoo-conventionally philosophical, and all-too-human-centered, debates about the ethics of harm reduction, articulated in terms of either consequentialist or deontological ethical theories. We argue that harm reduction understood in terms of phronesis - as a form of ethical practice based on knowledge derived from experience - is instantiated and available for investigation as a mediational cultural form. It is part of a drug use assemblage and as such it takes place and happens "online" just as much as it 
happens anywhere else: The online is a materially manifest dimension of "doing drugs" for many people, just as many other aspects of daily life today are subject to mediation and are empirically approachable in this dimension and on this basis.

\section{Phronetic Social Enquiry}

Reference to phronesis in the context of contemporary social enquiry is not in itself new. It is perhaps most closely associated with the work of the Danish sociologist Bent Flyvbjerg (2001; Flyvbjerg, Landman, \& Schram, 2007). Flyvbjerg calls for a radical shift in the self-understanding of social enquiry and for its redirection toward

enhancing a socially relevant form of knowledge, that is, phronesis (practical wisdom on how to address and act on social problems in a particular context) ... Phronesis in this sense is knowledge that is sensitive to its application in specific settings and is therefore able to manage itself (and more), which is what gives it prominence in social thought and action. (Flyvbjerg et al., 2007, p. 1)

This reorientation of social enquiry is one which contains a specific dissolution (though perhaps not the complete erasure) of the "distance" between the researcher and the researched. For instance, it aims to produce "situated knowledge about how to understand and act in contextualized settings, based on deliberation about specific sets of values and interests"; to "produce intimate knowledge of localized understandings of subjective human relationships"; to increase understanding and effect change "in specific contexts rather than questing after the ghost of an abstract knowledge"; and to produce knowledge that "grows out of intimate familiarity with contextualized settings ... tacit knowledges and skills, that cannot be taught a priori but grow from the bottom up" (Flyvbjerg et al., 2007, p. 2). Phronetic social science as an activity, we suggest, effectively acknowledges an affinity, even a coterminality, between itself and the social world conventionally considered the object of inquiry. It positions itself within a unitary scene of shared phronetic aspiration and ambition: Both phronetic social research, through engagement with the subject matters toward which it directs its attention, and the phenomena and processes of sociality itself, are viewed as equally ethically oriented toward that which matters and has value. One could thus say that harm reductionists of all shades-institutionalized, authoritative, and "from above," or "from below" at the level of everyday drug use practicesshare the same "good aims," whatever the difference between their rationales, and that this sharing is inclusive of drug takers and drug-taking itself. In other words, it can be acknowledged that no one or nothing (neither a person nor, e.g., a drug scene assemblage or milieu) actively wills drug-related harm as such.

Phronetic social science differs from traditional social science in that it rejects the privileging of the epistemic principle of modernity that expert knowledge alone can solve the social problems that it abstractly identifies and describes. It recognizes that the capacity to "live better" or to "live well" in relation to such things as the epochal dysfunctionality surrounding the relationship between drugs and society is located within the nexus of practices that constitute the sociopolitical context of a society and the specific constellation of relationships to the supposed "source"-in this case, the conventionally hypothesized "cause" - of harm. This is more generally the case with whatever supposed "social toxin" is singled out as a source of harm to individuals, groups, or society as a whole. The Flyvbjergian account of phronetic social science acknowledges that the social subject in a specific situation and from a particular perspective already knows the risk/danger of harm. No matter how well or how badly social subjects are able to address and live with the risks and dangers associated with certain social situations, the fact is they are living such situations. The traditional academic researcher only knows about them and produces knowledge about them (in Aristotle's schema this corresponds to episteme). The argument of phronetic social science is that episteme without phronesis will always fail to 
accomplish a properly ethical relationship to the "problem" and that "social problems" are always contiguous with the question of how to live well.

This approach thus recognizes the specific value of what is learnt/known from this living-out, or living-with, "the problem" - in our case, the problem (and the undertaking) of "how to live well with drugs." Emphatically, it does not mean that only those who are actual drug users can participate in the working out of how to live well with drugs (such that all social drug researchers should become drug users so as to better understand the reality of drug-taking). But it does call for valuing what can be learnt about how to live well with drugs from the specific relationships drug users have with drugs and from within the ecology of practices that encompass their drug use. As Stengers (2005, p. 187) states, "no theory gives you the power to disentangle something from its particular surroundings." This involves more than allowing the "voice" of drug users to be heard and learning from what it has to say-although we do contend this is one implication. It also involves paying attention to how drugs and drug use affectively influence and give form to communicative drug milieus. A more important implication is that attaining phronesis with respect to drugs involves considering how practices of researching the drugs field intersect and interact with the practices of drug-taking and drug culture more widely. (The research of harm reduction itself - either in practice or as a substantive theme-is essentially a part of the same ecology of practices.) Drug researchers and drug takers are thus to be viewed as located in different, yet overlapping, situations, and are thus equally oriented toward the same "ethical problem" with respect to drugs. Whether we should indeed continue to refer to this as the problem of harm reduction at all or whether it is better to speak of the "quest to get along well with drugs" remains to be seen.

\section{The Mediation of Drug Culture and the Study of Online Harm Reduction}

To meet the universe of drug-taking half way, phronetic social scientists must be prepared to divest themselves of the epistemological privilege normatively afforded to the discourse of representation along with its supposed power of truth telling, understood in terms of the power to distinguish between veridical representation and misrepresentation. Rather than mediate between one realm of "the real" and its representation in the account (logos) given of it-a "spectator theory of knowledge" (Frank, 2007, p. 56) - phronetic social science recognizes that knowledge is always relational, dialogical, and participatory (Frank, 2007). We argue that in the context of researching online drug culture, this difference corresponds to the transition from the age of mass media to the age of networked media. So, when considering harm reduction in the contexts of online drug culture, what needs to be understood and clarified is not, for example, how harm reduction and drug scenes are represented "in the media" or "by media" (including technical reports and medical textbooks as much as TV, newspapers, etc.) but rather how drug scenes have come to inhabit media-how they are literally in the media, such that we can identify them meaningfully as being in media res (in the midst of things).

The study of online drug culture on which this article is based was carried out as part of a multiresearcher, transdisciplinary project examining the roles of trust and empathy in online communications around "situations of extremis." Boothroyd is a media theorist/philosopher whose background includes writing on drugs and drug culture; Lewis is a sociologist of health and illness experienced in the research of online communities. These biographical details are noted because, consistent with our theoretical starting point, such parameters are materially relevant to the process of developing a research design and methodology to meet the research object as such. (The point we are making here is that every research situation is unique, not simply a scenario in which the conventions of professional expertise and skills are deployed by anyone-whoever or by-any-means-whatever.) It is not so much the case that there are few conventions to simply adopt and apply to the study of online life, but that every research project is contingently constituted by the assemblage, or the ecology of practices, 
with which the research process "conjoins." Expressed simply, our study is of the online drug scene it is enmeshed with (the "of" in this phrase being a double genitive.)

A simplistic way of thinking of online drug culture is to think of it as existing "on the Internet" or "on the web." The Internet is conventionally thought of as a medium, the means by which Internet culture is carried. The Internet is, of course, a technical apparatus and infrastructure comprising of globally interlinked hardware devices of many kinds, software and cables, and so forth. The web, on the other hand, is ostensibly a metaphor expressing a popular way of imagining the operation of supposedly higher level fluid, dynamic, and evolving connections between entities - between people, websites, platforms, organizations, governments, lurkers, stalkers, texts, images, videos, software programs, and protocols communicating with one another, and so forth, ad infinitum. But given our characterization of online drug culture as the (Internet/web) manifestation of drug culture per se, studying it, we contend, should begin by considering how various scenes are internally and externally bounded in relation to everything else online, and not least by the various technical aspects of platforms and programs that determine each scene's communicative capacities. It is in view of this that we devised a framework for examining what we think of, by way of another common metaphor in social science, as a "cross section" of that culture - effectively a sample, a sort of biopsy of the culture as a whole. Any such cut is a pragmatic decision taken in relation to many variables, but these were perhaps the most significant for our study: (1) variety of data gathered across a manageable number of online settings, (2) suitability of the sample in relation to the subject matter, and (3) diversity of drugs and drug culture practices - necessarily limited by precisely such research design decisions.

A communicative environment dedicated to drugs and drug use that expresses a specific cultural formation within the wider, open, hyperlinked system can be considered an entity based on how it is bounded (Paul, 2007). This is so in the same way that there are disciplinary conventions that determine and define, for example, the kinds of objects of study that are normatively considered to belong to one discipline rather than another and are investigated by means of methodologies established and legitimated within that discipline. While online communications are in reality fluid, dynamic, and indeterminately interlinked, there are nonetheless obvious candidates that can serve as relatively stable online settings. We therefore decided to focus on a set of web forums, "story sites," and blogs that between them cover three relatively distinct typologies of drug use. These are "novel psychoactive substances" (NPS)/“legal highs,", "addictive drug use," and "non-medicinal use of prescription drugs.",

\section{Method and Research Design}

Multicase study research (MCR) is a method that allows a particular phenomenon, concept, or function (the quintain) to be simultaneously examined across a set of singular, unique cases in order to explore the quintain in multiple "natural," context-bound settings (Stake, 2006). The quintain of the project of which our study is a part is trust and empathy in online drugs culture (and it was from the investigation of this quintain that harm reduction, or rather the phronetic dimension of "harm reduction from below," was to emerge). The set of "cases" to be studied addresses the need to break down the quintain into manageable parts and to investigate its components in several different environments. In MCR, a case is considered a bounded entity (Stake, 2006). For example, a single online forum could be a case, but a theme such as Internet privacy could not (it could, however, be a quintain). A case is not an abstraction but an empirical entity and, being bounded, has an outside (which can be explored by gaining context, e.g., by following links) and an inside (e.g., characterized by cumulative selfreference and reflexivity in general). It is thus able to express a sense of place and is territorial. These factors play a key role in determining the scope of MCR projects (Baxter \& Jack, 2008; Stake, 1995, 2006). The multicase approach allows the study of both a variety of cases while preserving the individuality of each case as a research "object" identified on the basis of its unique boundaries. 


\section{Scoping and Sampling}

In qualitative multicase research, potential study sites are chosen after initial investigation of the subject matter (Abma \& Stake, 2014; Darke, Shanks, \& Broadbent, 1998; Stake, 2006). Monitoring prospective study sites is a common starting point for Internet research, as it allows the researcher to gain a sense of what is happening on the site, establish its accessibility and eligibility for study, and glean the research ethics issues that may need addressing (AoIR, 2012; Gavin, Rodham, \& Poyer, 2008; Riley, Rodham, \& Gavin, 2009). ${ }^{8}$ Initial scoping for our project began with online searches using Google, Yahoo, and DuckDuckGo. For each drug use typology, we identified a number of possible study sites. Cases were eventually selected on the basis of their accessibility and the degree to which they offered insight into drugs discussions online and facilitated dialogue and information exchange. For each drug use typology, we eventually chose a forum, a collection of blogs, and a story site. The forums had to be active (posted to in the last 2 weeks), with more than 500 members, and with publicly accessible posts, meaning membership is not required to post messages, and all content is archived and searchable. An inclusion criterion for the blogs and story sites was that they had been posted to within the previous 3 months. Story sites are defined as sites that facilitate the telling of personal stories related to drug use (but are not forums or blogs). They were deemed suitable study settings if they facilitated dialogue between a variety of individuals (drug users, clinicians, friends, and family members). All settings were then assessed for their "learning potential" (Abma \& Stake, 2014, p. 1152) and potential to contribute to knowledge about the quintain. The entire study, then, comprises nine cases: (1) an NPS/legal highs forum, (2) a collection of NPS/legal highs blogs, (3) an NPS/legal highs story site, (4) an addiction forum, (5) a collection of addiction blogs, (6) an addiction story site, (7) a nonmedicinal use of prescription drugs forum, (8) a collection of nonmedicinal use of prescription drugs blogs, and (9) a nonmedicinal use of prescription drugs story site. All exclusively use the English language.

Data were collected through nonparticipant observation conducted over 11 months. Cases were observed simultaneously to aid comparison. The observation involved passive immersion in the settings: reading content, collecting posts, and other information representative of the community, its nature, interests, and ethos. To collect wider contextual data appropriate for multicase analysis, links to other websites and visual and audiovisual content beyond the settings were explored and recorded. As well as observing content being produced in real time, we also collected archived posts. This approach mimics how both lurkers and active members use sites and allows the researcher to gain a sense of the temporality of online spaces (Hine, 2000).

Grounded theory generally involves the simultaneous collection, analysis, and comparison of data, as well as memo writing (Corbin \& Strauss, 2008). All data were converted to PDF and initially coded line-by-line using Nvivo (version 10). Subsequent data collection was based on the ongoing analysis of the setting under scrutiny, ensuring that data collection became more refined as the analysis progressed. Some reflective notes and memos were taken during coding, allowing links to be made between codes; other notes were taken in the context of discussions of literature and the development of theory.

Given the limited space, our discussion focuses on four of the case studies. Moving beyond description to detailed analysis is a challenge for multicase studies (Flyvbjerg, 2006), as they produce very large amounts of data. The four cases we draw on - chosen for the particularly interesting ways in which harm reduction is enacted - are (1) the NPS/legal highs forum, (2) nonmedicinal use of prescription drugs blogs, (3) the nonmedicinal use of prescription drugs forum, and (4) the NPS/legal highs blogs. While harm reduction was evident in the other cases as well, we believe that these four cases adequately illustrate our argument that harm reduction in online drug culture is best understood as a form of phronesis. ${ }^{9}$ 


\section{The Online Life of Harm Reduction}

By providing access to peers and similar others to communicate about drugs and drug use practice, the online settings allow harm reduction to flourish. Like the settings themselves, harm reduction does not take a singular form. While online harm reduction clearly represents a shift in who is speaking about harm reduction, the very notion of "online life" also begs the question of what speaks. Although the "movement" has grassroots origins, the discourse has arguably become institutionalized and professionalized and then represented back to the drug users who were once at its forefront and vital center (Irwin \& Fry, 2007). With the proliferation of online drugs culture, harm reduction in these settings is returning to the habitus of drug use and to the horizontal exchanges between drug users. The result is that harm reduction is more directly based on the singular, but yet shared, interests of each scene and the specific drug cultural milieus that evolve and thrive in them. The differences between the kinds of harm reduction apparent across the four cases, we contend, are essentially cultural and shaped by the parameters of the particular milieu they belong to. To analyze the nuances of harm reduction across the cases, we first provide some description of how it is enacted and facilitated in each.

Turning first to the NPS/legal highs forum: harm reduction plays an integral role in how drug use in this setting is constructed - and how out-groups (such as medics, casual users, and nonusers) are framed. While harm reduction talk informs site users of safe practice and allows them to draw on their collective experience, there are also setting-specific limits as to what is shared: neither injecting drug use and users nor information about injection are welcome, as injecting is deemed inconsistent with the "identity" or "spirit" of the forum. Injecting drugs is contrary to the specific ethos of harm reduction this scene considers itself to live by. For example, "I am not willing to give you advice on injection" and "we do not support injection of RC's" (research chemicals). Yet the policing of this ethos through "house rules" on what may and may not be discussed arguably buys into the popular stigmatization of injecting drug users, witnessed in the casual use of the denigrating terms "junkie" and "smackhead."

The nonmedicinal use of prescription drugs blogs showcase quite different versions of harm reduction. They provide information to educate their readerships and are keen to build traffic to the blog by, for instance, encouraging readers to comment and ask questions: "please ask me any questions," "you can always talk to us, message me any time." Blogs are a one-to-many communication setting, allowing authors to set themselves up as "experts" on drug use. At the same time, authors are keen to position themselves as equally vulnerable to the consequences of drug use, for instance, by stating that they too are risking their own lives: "anyone can overdose at any time." They typically see it as their responsibility to discuss both the "good" and "bad" sides of drug use, even giving detailed instructions (including a checklist of items to have on hand) when injecting for the first time. For example, "you'll need some sterile water, never use tap water" and "flick away any bubbles and you're nearly ready to inject."

On the nonmedicinal use of prescription drugs forum, harm reduction as such is not as frequently mentioned as it is in the other settings but is constantly made discursively relevant with members encouraging one another to choose safer options. Harm reduction in this setting is interwoven with milieu-specific ideas of what it is to be a credible online drug user, with much of the proffered advice being used to bolster the advising member's credibility as an expert user rather than the advice seeker being at the heart of the conversation. For example, "personally I wouldn't even bother with codeine, not worth the effort" and "if anyone wants advice I've been doing this for ten years now."

The NPS/legal highs blogs give readers practical advice as well as detailed information on particular "research chemicals," with authors consistently reaffirming what they consider to be good practice, such as measuring substances carefully, optimizing doses (erring on the side of caution), and having a sober "sitter" on hand. The comments systems on these blogs differ from those on the non-medicinal use of prescription drugs blogs; here it is not only the blog authors who offer advice on best practice. Commenters (among them many psychonauts and amateur Alexander Shulgins) ${ }^{10}$ 
discuss safe drug use among themselves at great length, taking the words of the blog author as their point of departure. They join in the cautionary culture of the setting: "you know that's too much, fuck!" "Expert" personas are much less noticeable than on the nonmedicinal use of prescription drugs blogs; commenters develop, question, and advise one another, without relying on the blog author. This illustrates how overall "site functionality" - technical affordances such as the ability to post images as well as text, and codes of practice such as moderation and house rules-impacts on communicative participation and exchange, and hence on what might be called communicative harm reduction. So, too, does the posting of images ('just bought this bag of brown, does this stuff look right to you?') and hyperlinking to other sources, such as YouTube instructional videos. ${ }^{11}$ Harm reduction and safety tips are widespread on both NPS/legal highs blogs and forums, with commentators (interestingly, not the blog authors themselves) urging fellow users to be "sensible." They urge one another to find a "balance" and to keep things in "moderation"- - not only in order to be safer but, in some instances, to help ensure that particular legal highs remain legal. These online life goals vis-à-vis drug use, the ethos of the community, and harm reduction practices are overlaid, interwoven, and inseparable, representing a nexus of what we earlier referred to as an "ecology of practices" - knowledge practices, behavioral practices, social practices, educational practices, ideological practices, and others, which together indicate the vitality of the online life of drug cultures.

The above descriptions give some idea of how cultures of harm reduction are manifested and expressed and provide a sketch of how each setting-specific discourse is linked to other elements of online communication and ideas of space, place, scene, codes, and community. There is clearly no single discourse of harm reduction or generic set of practices; discourses are polyvocal and evolving. And while these discourses do not privilege normative, institutional standards of "propriety" and scientific truths and evidence surrounding drug use, they are neither devoid of references to, nor immune to incorporating, such aspects as participants pursue "narcological" experimentation. This, we suggest, exposes the paucity of the idea-frequently expressed in the literature (Davey, Schifano, Corazza, \& Deluca, 2012; Norman, Grace, \& Lloyd, 2014; Tackett-Gibson, 2008) - that "peer-topeer" sharing around drug use is that of "incorrect" or "harmful" information. For again, one has to ask: by what standard and according to what authority are veracity and harmfulness to be measured and evaluated?

What we see across these four cases are processes of countering useless information, as defined by experience in situ. It is true that the tenor of the discussion and advice in these online settings often overlap with "official" and off-line discourses that are, perhaps, partially appropriated (e.g., "if you can avoid it, don't share needles") or at least overlap with normative, commonsense talk about the minimization of risks and best practices. But it is also true that through the lens of experience and a form of collective trial and error, one can discern a countervoice to the mainstream domination and control of the notion of harm reduction. Such communicative sharing creates a sense of authority and value, not so much for individuals (though in some online communities, there is often an element of that) but for the "voice" of practical wisdom or "know-how" as such, in other words for the scene itself, or what we call the milieu. The milieu is thus neither simply a "who" nor a "what," but a technomediational form of drug culture in the sense that we can begin to look beyond the question of who or what "decides" with authority how "harm reduction" is to be understood. The milieu, in effect, has agency.

When thinking about who can talk about and define harm reduction in these contexts, the question of discursive power comes to the fore (Mitra, 2004): "in the internet space power is related to the eloquence of the voice, the way in which a voice can link itself with other voices and in combination garner power" (Mitra \& Watts, 2002, p. 489). The emergence of online life is accompanied by significant shifts in such power: Without the usual barriers to publicity and unlimited scope for access and distribution, power has shifted from what can be considered a top-down, professionalized discourse of harm reduction (Irwin \& Fry, 2007) to one that is peer generated and user led. This is not to 
say that online harm reduction discourses are "true" or "superior" or that they are uninfluenced by "official" discourses (Ekendahl, 2014), but they do signal the integration of harm reduction as both idea and practice with multiple drug cultural milieus and the voices that populate them. "Voice" in this sense is just one among several power vectors of a given milieu.

Rather than being a "great equalizer" as it is often imagined, the Internet underpins a multiplicity of drug scenes and harm reduction cultures. Across some of these, inequality, stigma, marginalization, prejudice, and antagonism persist around various setting-specific notions of drug use impropriety. For instance, this is the case around injection and heroin use generally, among non-heroin users. Social media have the power to give voice as well as to silence those who are already marginalized (Baym \& Boyd, 2012). In the online settings that we observed, the boundaries of acceptable discourse are collectively policed. What is deemed acceptable expression in online communities is policed through numerous means, including wanting to remain a good representative of the group (Davey et al., 2012). This brings into focus the potential disconnect between the discursive acts of harm reduction and its lived reality - which is why online settings must be considered as spaces of study in their own right rather than as windows on the off-line practice of drug use. Site norms and ethos differ widely (BarLev, 2008; Lewis, 2014). Along with the functionality of platforms, they play a key role in determining who has voice and who is silenced. But as noted above, "having a voice" cannot be reduced to "access to the public sphere." The latter, in any case, is generally the place of drug use opprobrium and antithetical to the very raison d'etre of online drug culture.

\section{The Process of Doing Drugs Well}

A key characteristic of the dominant, public-sphere harm reduction discourse, reflected in much of the academic literature on the subject, is its focus on outcomes, consequences, endings, effects, and implications of illicit (in the wider senses of "improper" or "inappropriate") drug use. This may in part be due to the prominence of outcomes in the disease and criminal models of drug use, preoccupied with addiction, death by overdose, unwanted side effects, criminality, and violence. The panoramic perspective of such harm reduction encompasses the desire to counter the socially and individually harmful consequences of the prevailing cultural situation around drug use. Needless to say, it is less open to considering what "doing drugs well" means from the perspective of drug-taking itself. How drug takers might benefit from harm reduction in pursuit of their drug-taking lifestyles remains a taboo subject.

Like it or not, this is, we suggest, what harm reduction is about within online drug culture. Articulations of harm reduction found online are complex, sometimes contradictory, sometimes "tribal," and contingent upon a mix of social, technological, and pharmacological factors. Perhaps the most generic difference online drug scenes introduce into the wider culture of harm reduction is the emphasis on the processes of drug-taking rather than its outcomes. By this we refer to how drug-taking becomes part of the life process of drug users for whom the gamble and the risks involved are a noble wager in relation to their "projects" of achieving some desired affective alteration or other. This is not to say that the outcomes of methods, approaches, and techniques are not reported on. But warnings and cautions shared within online settings - highlighting risks of death, addiction, and serious injury ("you're going to die," "mate watch your doses," "DO NOT START INJECTING," "DON'T RISK IT," "that combo can kill you") — contribute to a climate of "harm reduction" from the perspective of shared understandings about the aim of "living well with drugs." These are drug cultural settings in which process is key to saying "yes" to drugs and "yes" to life. Far from being antithetical, these two "yesses" are widely considered to be indistinguishable (see Boothroyd, 2006). It is not unwise to take "dangerous drugs." It is, in this other sense and from this other perspective, unwise not to-a monstrous perspective, no doubt, in most people's eyes. 
What we have referred to as a preoccupation with process is evidenced on the nonmedicinal use of prescription drugs blog in the discussion of, and provision of instructions for, injecting, alongside acknowledgment that even "expert" authors are at risk of overdose. Process on the NPS/legal highs forum takes a different form, with members referring to themselves as "researchers" and their drugtaking as "research." The vocabulary used when discussing "research" is one of exploration and scientificity (or pseudo-scientificity): "going to conduct some experiments this weekend," "I'll report my findings," and "urge to discover." At the same time, the forum extolls the use of precise measuring devices (scales, pipettes, thermometers, allergy tests, and etc.) and advises on such diverse matters as the best doses for first-time users and the best compounds for rectal administration. "Researchers" are also interested in the process, or practices, leading up to the "experiment" and are keen to share ways of limiting come downs and side effects, suggesting the use of vitamins and supplements that can ease negative symptoms. The expression of such a particular "scientificity" is at the same time a marker of in- and out-groups, as it renders its participant-members distinct from casual, recreational, or naive users: It is not, in this particular case, about pleasure, but about the "spirit of inquiry" into "altered states." When this formalized process is challenged, it is met with a backlash from members who reassert their position as "researchers." In observing this scene, we noted how this assertion of the research character of drug use practice allows participants to deproblematize their use, framing it as something noble and to be defended, key to the values the site espouses and to its identity within the wider ocean of online drug culture.

The nonmedicinal use of prescription drugs forum is likewise a "processual environment," albeit encompassing a quite different ecology of practices highlighting the phronetic idea of a "life course" of drug use. In this setting, the life course of drug use is seen as a sign of one's credibility as a drug user and online content creator. Members, for example, state how their tolerance is higher now than when they were just "wee kiddos." They speak of favoring different drugs at different times in their lives and stress the need for members to understand their own bodies and how they react to different drugs. For example, "everyone has a different reaction, so feel free to disagree" and "not everybody is the same when it comes to these things." There is a clearly shared culture of understanding how different people will have different experiences, and over time will likely change themselves, and that their experiences are as valid as anyone else's.

\section{Conclusion: Harm Reduction as Phronesis or "Doing Drugs Well"}

Across a broad spectrum of online drug scenes, our study revealed a culture of communicative sharing around illicit drug use that demonstrates a popular culture of "best practice" rooted in experience and know-how of illicit drug-taking. The manifest culture of caution, care, and responsibility, the management of risk and danger in relation to drug-taking, however questionable its "efficacy" may be from the perspective of various forms of "drugs expertise" - including harm reduction expertise - can be viewed, firstly, as evidence of a general and widespread "harm reduction ethos."

To conclude, we return to how harm reduction practiced from below problematizes the conventional understanding of harm reduction, which we argued cannot escape the question of who or what has the authority to define harm reduction. We did not set out to empirically assess whether or not online drug culture contributes to (or undermines) harm reduction, as it is understood from within its various institutional settings and policy deployments. Nor did we attempt to measure the effectiveness or impact of the various kinds of co-created drug use knowledge and advice on the actual practices of drug users. Our study instead aimed to show how drug users, as evidenced in a variety of online drug cultural settings, are involved in working out for themselves how to get along better with the drugs they take - on their own terms. Every drug taker's "terms" are arguably unique; drug use situations differ widely and no doubt partly determine how any particular drug use scenario turns out for those involved. But at least for the participants of online drug culture, their terms of engagement with drugs 
are also partly constituted and expressed by the online spaces in which this culture takes place and is shared. These are scenes in which best practice and the meaning of "best practice" are continuously worked out in conjunction with and within a multitude of drug-taking contexts. In conjunction, that is, with the wider dynamic ecology of drugs and drug use practices, which include informational practices such as publicity, communication, and dissemination. Some of these are institutional and scientific (including social scientific). Many are not. But they all directly or indirectly find their way into the online deliberations surrounding the drug use of online users by, literally, becoming part of the milieus of their drug use.

In many ways, it is only too easy to identify evidence of a harm reduction ethos in such cultural spaces, but doing so inevitably proceeds on the basis of a concept of harm reduction that has its normative roots in wholly other kinds of "institutional" cultural spaces. ${ }^{12}$ Its discursive power shapes the thinking of social drug use researchers and drug users alike-how could it not (for we authors as much as anyone else)? To a degree this is reflected also, as we have shown, in harm reduction talk in online drug culture settings. The practice of drug-taking, however, is aimed at performing drug use in such a way that it accomplishes something for the user-a particular high, a mood change, even oblivion - to make the next moments of life as it is lived "better" than the present. So while raising the issue of who has the power to define harm reduction is crucial, it is equally important to question the assumption that the "primary issue" for drug users (as individuals, as a group, or as a community) is that of potential harm (notwithstanding the day-to-day concerns that arise from impurities, the unidentifiability of powders and pills, the availability of clean drug paraphernalia, illegality of acquisition, and etc.- -all of which are indisputably sources of potential harm.) For at least some people, their drug-taking practices are aimed at reducing the "harm" a life of sobriety inflicts on their projects of living well.

It is difficult not to think of the quest for a "healthier" relationship to drugs, on a personal or societal level, other than on the basis of health and well-being as defined by medical discourses (along with other juridical and political discourses surrounding acceptable behavior). It would then follow logically that the harm reductionist approach toward for instance addiction should seek its decriminalization and argue for its medicalization. After all, the underlying assumption is that drugs are first and foremost "medical substances" and that the pharmaco-medical management of their use and their users is ultimately what is propitious. But what is obscured or concealed by this dominant model of harm reduction - which with all good (moral) intentions aims to alleviate the perceived harms of drugtaking in anything less than "ideal circumstances"-is the presumption that lives lived "on drugs" have little or nothing to offer in terms of the account (logos) they might give of themselves. Our claim is that the online dimension of such "drug lives" is a dimension of culture, a space or place where, at least to a degree, this becomes possible.

What we have observed in such online settings is the working out of a multifarious range of relationships to drugs by users, relationships that reveal aspects of drug use aimed at getting along better with drugs. These are relationships in which drugs themselves, in a kind of symbiosis with life online and within a wider ecology of practices surrounding their use, aim for a kind of practical wisdom (phronesis) about drug use. While individuals may judge one another around what they consider to be correct or incorrect, good or bad advice, and with regard to who among them speaks with authority, judgment per se is less important than the collective quest of "getting it right" in practice and in situ.

It is this that warrants, we suggest, referring to scenes of practice as phronetic. While expert knowledge (episteme) - well or poorly appropriated - figures in these cultural scenes to a greater or lesser extent, and skill or craft (techne) with respect to drugs (handling, sourcing, preparing, injecting, and etc.) is highly valued, such forms of knowing are, for the drug user who has "just said yes" to their drug, subservient to the aim of "doing drugs well." What doing drugs well means, however, cannot be generalized. It is possibly not only different for each individual but also for every single instance of 
use, because every situation is unique and always shaped by multiple variable parameters - the drug in question, the supposition of its purity, the current health status of the taker, the presence of friends, polydrug use, and so forth. But the meaning of the expression is, emphatically, neither the point nor directly the concern of practical wisdom: Phronesis refers to the practice or performance of life itself and, by definition, doing it well can only be learned from life itself.

\section{Declaration of Conflicting Interests}

The author(s) declared no potential conflicts of interest with respect to the research, authorship, and/or publication of this article.

\section{Funding}

The author(s) disclosed receipt of the following financial support for the research, authorship, and/or publication of this article: The research for this article was funded by a consortium of UK Research Councils and other public agencies (see note 5 for details). The authors received no financial support for the authorship or publication of this article.

\section{Notes}

1. Tony Bennett speaking in the film Amy (Asim Kapadia, 2015).

2. For an anthropological perspective, see Rudgely (1998).

3. We privilege the term "milieu" for the emphasis it affords to notions of place and space as fluid constructions, and because it allows us to bring into focus the manner in which space and place are a function of connections facilitated by technical means, communications technologies in particular. Our use of the term is also influenced by Deleuze and Guattari's discussion of the milieu as a "living thing" (see, e.g., A Thousand Plateaus, 1987, p. 313). The online drug milieu is composed of many different elements, including (at least) drugs, drug use practices, drug discourses of various kinds, information, reports (technical, experiential, and etc.), archived material, hyperlinks, and a range of technical affordances facilitated by online platforms.

4. See Aristotle, Nicomachean Ethics 1142a.

5. Full details of the Shared Space and Space for Sharing project can be found here: http://www.space4sharingstudy.org. The project is funded by a consortium of UK Research Councils, ESRC, AHRB, EPSRC, along with Dstl and CPNI. Other studies within the project are investigating online scenes related to terminal illness, natural disasters, suicidal ideation, and organ and tissue donation.

6. As a drug cultural term "legal high" is problematic, it does not necessarily signify the true legal status of a drug or "product." It is commonly used by those selling and buying "legal highs" via the Internet, irrespective of the destination and place of consumption of the wares.

7. These categories, or drug use typologies, do not take their lead from any conventional taxonomy-pharmacological, pharmacopoeial, juridical, medical, and so forth. They were selected simply on the basis of how drugs and drug use figure in the online drug scenes we study. Whether such "bottom-up" characterizations of particular substances and user-generated interests and themes that emerge in relation to their use is in accordance with, for example, scientific discourse, is not a focus of attention here; our study simply "follows" such classifications, experiences, and understandings insofar as we found them in online drug culture.

8. This research project attained ethical approval from the Lincoln University Research Ethics Committee. To safeguard the anonymity of the sites and contributors to the sites, we use aggregated rather than verbatim quotation (Bond, Ahmed, Hind, Thomas, \& Hewitt-Taylor, 2013).

9. In this respect, we borrow from the grounded theory perspective on the generation of theory from small-scale, in-depth qualitative research (Darke et al., 1998; Houghton, Casey, Shaw, \& Murphy, 2013; Stake, 1995, 2006).

10. Alexander Shulgin (1925-1914), psychopharmacologist and author, is often revered as a countercultural figure in these settings.

11. For a discussion of YouTube drug-related educational videos, see Manning (2014). 
12. See Duxbury (2015) for an interesting reflection on the "ritualistic" construction of multiple "moralities" surrounding drug use in online drug cultures. Here, we have attempted to articulate how the ethical dimension of what we have referred to as "doing drugs well" can be understood to find its expression in online drug culture.

\section{References}

Abma, T. A., \& Stake, R. E. (2014). Science of the particular: An advocacy of naturalistic case study in health research. Qualitative Health Research, 24, 1150-1161.

Association of Internet Researchers (AoIR). (2012). Ethical decision making and internet research. Retrieved March 17, 2015, from http://aoir.org/reports/ethics2.pdf

Aristotle, Nichomachean Ethics, Loeb Classical Library, Vol. XIX.

Bar-Lev, S. (2008). "We are here to give you emotional support": Performing emotions in an online HIV/AIDS support group. Qualitative Health Research, 18, 509-521.

Baxter, P., \& Jack, S. (2008). Qualitative case study methodology: Study design and implementation for novice researchers. Qualitative Report, 13, 544-559.

Baym, N., \& Boyd, D. (2012). Socially mediated publicness: An introduction. Journal of Broadcasting and Electronic Media, 56, 320-329.

Bond, C., Ahmed, O. H., Hind, M., Thomas, B., \& Hewitt-Taylor, J. (2013). The conceptual and practical ethical dilemmas of using health discussion board posts as research data. Journal of Medical Internet Research, 15, e112.

Boothroyd, D. (2006). Culture on drugs: Narco-cultural studies of high modernity. Manchester, England: Manchester University Press.

Butler, J. (1997). Excitable speech: A politics of the performative. New York, NY: Routledge.

Corbin, J., \& Strauss, A. (2008). Basics of qualitative research 3e: Techniques and procedures for developing grounded theory. Los Angeles, CA: Sage.

Darke, P., Shanks, G., \& Broadbent, M. (1998). Successfully completing case study research: Combining rigour, relevance and pragmatism. Information Systems Journal, 8, 273-289.

Davey, Z., Schifano, F., Corazza, O., \& Deluca, P. (2012). e-Psychonauts: Conducting research in online drug forum communities. Journal of Mental Health, 21, 386-394.

Deleuze, G., \& Guattari, F. (1987). A thousand plateaus. Minneapolis: University of Minnesota Press.

Duxbury, S. W. (2015). Information creation on online drug forms: How drug use becomes moral on the margins of science. Current Sociology. doi:10.1177/0011392115596055

Ekendahl, M. (2014). Heroin narratives: Normalization and demonization of heroin use at a Swedish online message boar. Sociology Study, 4, 714-727.

Flyvbjerg, B. (2001). Making social science matter: Why social inquiry fails and how it can succeed again. Cambridge, MA: Cambridge University Press.

Flyvbjerg, B. (2006). Five misunderstandings about case study research. Qualitative Inquiry, 12, 219-245.

Flyvbjerg, B., Landman, T., \& Schram, S. (2007). Introduction: New directions in social science. In B. Flyvbjerg, T. Landman, \& S. Schram (Eds.), Real social science: Applied phronesis (pp. 1-14). Cambridge, MA: Cambridge University Press.

Frank, A. W. (2007). The feel for power games: Everyday phronesis and social theory. In B. Flyvbjerg, T. Landman, \& S. Schram (Eds.), Real social science: Applied phronesis (pp. 48-65). Cambridge, MA: Cambridge University Press.

Gavin, J., Rodham, K., \& Poyer, H. (2008). The presentation of pro-anorexia in online group interactions. Qualitative Health Research, 18, 325-333.

Hine, C. (2000). Virtual ethnography. London, England: Sage.

Houghton, C., Casey, D., Shaw, D., \& Murphy, K. (2013). Rigour in qualitative case-study research. Nurse Researcher, 20, 19-27. 
Irwin, K., \& Fry, C. L. (2007). Strengthening drug policy and practice through ethics engagement: An old challenge for a new harm reduction. International Journal of Drug Policy, 18, 75-83.

Kapadia, A. (Director). (2015). Amy. Film4/Krishwerkz Entertainment.

Keane, H. (2003). Critiques of harm reduction, morality and the promise of human rights. International Journal of Drug Policy, 14, 227-232.

Lewis, S. C. (2014). A grounded theory analysis of the forms of support on two online anorexia forums. Unpublished doctoral thesis, Loughborough University, England.

MacKenzie, I. (2004). The idea of pure critique. London, England: Continuum.

Manning, P. (2014). YouTube, “drugs videos” and drugs education. Drugs: Education, Prevention and Policy, $20,120-130$.

Mitra, A. (2004). Voices of the marginalized on the internet: Examples from a website for women of South Asia. Journal of Communication, 54, 492-510.

Mitra, A., \& Watts, E. (2002). Theorizing cyberspace: The idea of voice applied to the internet discourse. New Media and Society, 4, 479-498.

Norman, J., Grace, S., \& Lloyd, C. (2014). Legal high groups on the internet: The creation of new and organized deviant groups? Drugs: Education, Prevention and Policy, 21, 14-23.

Paul, C. (2007). Hub and terminal: Developing a method for textual analysis on the World Wide Web. First Monday, 12, 1-16.

Riley, S., Rodham, K., \& Gavin, J. (2009). Doing weight: Pro-ana and recovery identities in cyberspace. Journal of Community and Applied Social Psychology, 19, 348-359.

Rudgely, R. (1998). The alchemy of culture: Intoxicants and society. London, England: British Museum Press.

Stake, R. E. (1995). The art of case study research. Thousand Oaks, CA: Sage.

Stake, R. E. (2006). Multiple case study analysis. New York, NY: Guilford Press.

Stengers, I. (2005). Introductory notes on an ecology of practices. Cultural Studies Review, 11, 183-197.

Stengers, I. (2008). Experimenting with refrains: Subjectivity and the challenge of escaping modern dualism. Subjectivity, 22, 38-59.

Stengers, I., \& Ralet, O. (1997). Drugs: Ethical choice or moral consensus. In I. Stengers (Ed.), Power and invention: Situating science (pp. 215-232). Minneapolis: University of Minnesota Press.

Tackett-Gibson, M. (2008). Constructions of risk and harm in online discussions of ketamine use. Addiction Research and Theory, 16, 245-257.

\section{Author Biographies}

Dave Boothroyd is a professor of media and culture and the director of research in the School of Film and Media, University of Lincoln, UK. He is the author of Culture on drugs: Narco-culture studies of high modernity (Manchester University Press, 2006), editor of the online collection Pharmacologies (JISC/Open Humanities Press, 2011) and Ethical subjects in contemporary culture (Edinburgh University Press, 2013). He is founding coeditor of the online journal Culture Machine. He is (until 2017) a co-investigator on the UK Research Councilsfunded project "Shared Space and Spaces for Sharing" (www.space4sharingstudy.org).

Sarah Lewis received her PhD from the University of Loughborough (2014). She is a sociologist of health and illness with special interests in online communications and peer-to-peer sharing around eating disorders. Since 2014 she has been working as a research fellow at the University of Lincoln, UK, on the UK Research Councilsfunded project "Shared Space and Spaces for Sharing" (www.space4sharingstudy.org). 